\section{Несплошные рубки в смешанных ельниках}

\author{
В. А. Ряхин ${ }^{1}$ \\ С. М. Синькевич \\ Петрозаводский государственный университет \\ Институт леса КарНЦ РАН
}

\begin{abstract}
АННОТАЦИЯ
В статье описываются возможные пути освоения сырьевого потенциала лесов I группы, которые в значительной мере определяются историей формирования и функциональным назначением насаждений. Результаты проведенных в них несплошных рубок свидетельствуют о достаточной устойчивости насаждений к интенсивным разреживаниям и обоснованности лесоводственных требований к технологии работ.
\end{abstract}

Ключевые слова: выборочная рубка, устойчивость насаждения, повреждения.

\section{SUMMARY}

Use of wood reserve potential of protective forests largely depends on the history of their formation and functionality. The results of selective fellings demonstrate the sufficient stand stability after intensive thinnings and the validity of silvicultural demands for logging technology.

Keywords: selective felling, stand stability, tree damages.

Начиная с конца XIX века в среднетаежных лесах Карелии довольно широко проводились выборочные рубки, при которых из древостоев изымались крупномерные деревья, а более мелкие и подрост оставлялись на дальнейшее доращивание. Проведение таких рубок было обусловлено неблагоприятной экономической ситуацией, гарантирующей сбыт только крупномерных высококачественных сортиментов. До 30-х годов XX века подневольно-выборочная форма хозяйства была широко распространена в районах средней и северной тайги. Выделение в различное время территорий с ограничениями режима лесопользования способствовало сохранению формировавшихся смешанных насаждений и фактическому внедрению в них выборочного хозяйства.

По мере неоднократной вырубки деревьев сосны и сохранения части подроста, главным образом ели, происходило постепенное замещение сосновых лесов на еловые с разной долей участия лиственных пород. Это связано с тем, что в естественной обстановке возобновление в сосняках черничных и на значительной площади сосняков брусничных шло преимущественно за счет ели или с большой долей ее участия. Предпосылками для этого являются регулярное и обильное (каждые 3-4 года) плодоношение ели, способность ее семян к про-

${ }^{1}$ Авторы - заведующий кафедрой лесного хозяйства и ведуший научный сотрудник

(C) В. А. Ряхин, С. М. Синькевич, 2003 растанию при более широком диапазоне влажности мха и подстилки, а также теневыносливость, имеющая решающее значение для выживания подроста. Семенные годы у сосны наблюдаются в 2-3 раза реже и, по мере увеличения географической широты района, недостаток семян оказывает все более заметное влияние на ход возобновительного процесса в сосняках $[4,6]$. В результате к настоящему времени на обширных площадях, относящихся к различным категориям защитности, сформировались смешанные разновозрастные насаждения, в которых присутствует, наряду с более молодыми деревьями ели, березы и осины, и старая ель в возрасте 140-200 лет. Разработка путей хозяйственного освоения этих насаждений представляет собой одну из сторон решения проблемы смены пород, и в частности - сосны елью [8], которая по-прежнему актуальна для Европейского Севера.

В насаждениях I группы лесов, согласно действующим Правилам рубок, не допускаются рубки главного пользования. Исходя из конкретных условий местопроизрастания, возраста отдельных пород, состава насаждений и других факторов, в настоящее время могут проводиться рубки омоложения, рубки реконструкции и др. Необходимость проведения тех или иных рубок в этих древостоях определяется не только напряженной сырьевой ситуацией в эксплуатационных лесах, но и состоянием насаждений, которые в силу своего возраста и комплекса прошлых антропогенных воздействий частично утрачивают свои целевые функции.

Применение на несплошных рубках техники, используемой на промышленных лесозаготовках, в большинстве случаев затрудняет выполнение лесоводственных требований. C учетом широкого диапазона характеристик древостоев, условий произрастания и условий заготовки на сегодняшний день лесосечные работы организуются на базе валки бензиномоторными пилами и транспортировки древесины модернизированными сельскохозяйственными тракторами МТЗ, а также форвардерами, выпускаемыми малыми сериями на их основе или более мощными отечественного или зарубежного производства. Результаты обследования ельников, пройденных несплошными рубками в течение последнего десятилетия, подтвердили перспективность всех этих технологий с точки зрения уровня, относительно приемлемого в интересах лесовыращивания.

Приведенные в табл. 1 данные о составе древостоев свидетельствуют о том, что в подавляющем большинстве случаев он изменился незначительно. Причиной этого явилась необходимость уборки спелых экземпляров ели, имеющих относительно большие размеры. Поэтому, хотя при отборе деревьев в рубку применялся комбинированный метод, средний объем стволов оставленной части древостоя оказался на 7-14\% меньше исходного.

Выборка по запасу тесно связана $\left(\mathrm{R}^{2}=0,92\right)$ с выборкой по количеству деревьев и составляет на треть больше eе, что также наглядно свидетельствует о преимущественной выборке более крупных деревьев. 
Таблица 1

Таксационные показатели насаждений

\begin{tabular}{|c|c|c|c|c|c|c|c|c|}
\hline \multirow{2}{*}{ 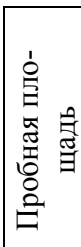 } & 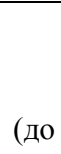 & \multicolumn{2}{|c|}{$\begin{array}{c}\text { Состав } \\
\text { древостоя }\end{array}$} & ки) & \multirow{2}{*}{ 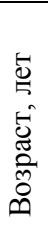 } & \multirow{2}{*}{ 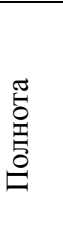 } & \multirow{2}{*}{ 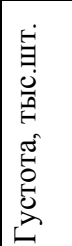 } & \multirow{2}{*}{ 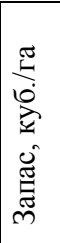 } \\
\hline & $\mathrm{E}$ & $\mathrm{C}$ & Б & Oc & & & & \\
\hline \multirow[t]{2}{*}{$1 \Pi$} & 5,8 & - & 2,5 & 1,7 & \multirow[t]{2}{*}{90} & 0,79 & 0,81 & 226 \\
\hline & 7,1 & - & 1,8 & 1,1 & & 0,57 & 0,64 & 164 \\
\hline \multirow[t]{2}{*}{$2 \pi$} & 3,3 & 3,1 & 3,6 & - & \multirow[t]{2}{*}{70} & 0,97 & 1,14 & 283 \\
\hline & 3,6 & 2,8 & 3,6 & - & & 0,73 & 0,96 & 207 \\
\hline \multirow[t]{2}{*}{$3 \Pi$} & 5,8 & - & 2,8 & 1,4 & \multirow[t]{2}{*}{90} & 0,86 & 1,03 & 243 \\
\hline & 6,2 & - & 2,6 & 1,2 & & 0,73 & 0,92 & 206 \\
\hline \multirow[t]{2}{*}{ 4л } & 8,4 & 0,3 & 0,8 & 0,5 & \multirow[t]{2}{*}{150} & 0,86 & 0,91 & 253 \\
\hline & 8,8 & 0,2 & 0,9 & 0,2 & & 0,41 & 0,55 & 113 \\
\hline \multirow[t]{2}{*}{ 5л } & 8,7 & 0,1 & 0,3 & 0,9 & \multirow[t]{2}{*}{150} & 0,73 & 0,85 & 223 \\
\hline & 8,1 & 0,1 & 0,4 & 1,4 & & 0,48 & 0,66 & 145 \\
\hline \multirow[t]{2}{*}{ 6л } & 3,6 & 2,4 & 1,4 & 2,6 & \multirow[t]{2}{*}{80} & 1,12 & 1,03 & 368 \\
\hline & 4,1 & 2,4 & 0,9 & 2,6 & & 0,74 & 0,83 & 238 \\
\hline \multirow[t]{2}{*}{ 7к } & 5,0 & 2,0 & 1,0 & 2,0 & \multirow[t]{2}{*}{130} & 0,59 & 0,61 & 229 \\
\hline & 7,0 & 2,0 & 0,9 & 0,1 & & 0,44 & 0,49 & 167 \\
\hline \multirow[t]{2}{*}{$8 \kappa$} & 5,0 & 1,0 & 1,0 & 3,0 & \multirow[t]{2}{*}{130} & 0,77 & 0,89 & 236 \\
\hline & 8,0 & 0,1 & 0,9 & 1,0 & & 0,52 & 0,69 & 158 \\
\hline
\end{tabular}

Таблица 2

Интенсивность несплошных рубок

\begin{tabular}{|c|c|c|c|c|c|c|c|}
\hline \multicolumn{7}{|c|}{ Выборка ( \%) на пробных площадях } \\
\hline 1 1п & 2 п & 3п & 4л & 5л & $6 л$ & 7 к & 8 к \\
\hline \multicolumn{7}{|c|}{ папасу на пасеках } \\
\hline 19,0 & 18,4 & 7,1 & 49,2 & 26,5 & 22,0 & 8,0 & 19,5 \\
\hline \multicolumn{7}{|c|}{ по запасу на делянке } \\
\hline 27,4 & 26,9 & 15,2 & 55,3 & 35,0 & 35,3 & 27,1 & 33,1 \\
\hline \multicolumn{7}{|c|}{ по густоте на делянке } \\
\hline 21,0 & 15,8 & 10,7 & 39,6 & 22,4 & 19,4 & 19,7 & 22,5 \\
\hline
\end{tabular}

В широком диапазоне интенсивностей рубки значительная вариабельность выборки никак не соотносится с основными исходными запасами, густотой древостоя или долей участия лиственных пород. В то же время следует отметить тесную положительную корреляцию $(\mathrm{R}=0,79)$ выборки по запасу на пасеках и среднего объема ствола до рубки.

Общая интенсивность вырубки лиственных пород колеблется в целом от 23 до 50\%. При наличии перспективного для дальнейшего выращивания поколения ели интенсивность разреживания варьирует от умеренносильной до сильной, но она также не связана с исходными параметрами густоты и запаса. Тем не менее основная цель данных рубок - уход за главной с экономической точки зрения породой - выполняется.

В ряде работ, посвященных выборочным рубкам в ельниках, отмечается $[1,3,5]$ большая опасность ветровала и утверждается, что предельно допустима интенсивность $30-35 \%$ с учетом деревьев, вырубаемых на волоках. Приведенные данные (табл. 2) показывают, что на обследованных участках интенсивность рубки отвечает этим рекомендациям и соответствующим нормативам.

Доля древесины, вырубленной на волоках, в общем объеме заготовки колеблется от 10 до 50\%. Для всех участков характерным является уменьшение интенсивности разреживания в серединах пасек по сравнению с территорией, прилегающей к технологическим коридорам, однако эта разница, как правило, не превышает одной трети.

В насаждениях, пройденных рубкой, выявлено от 10 до 40 шт./га поврежденных деревьев, что составляет от 1,4 до $3,9 \%$ численности наличного древостоя. Количество повреждений возрастает $\left(\mathrm{R}^{2}=0,81\right)$ с увеличением густоты древостоя. Наибольшее количество повреждений (95\%) на участках с хлыстовой трелевкой (пп 1-3) приходится на ошмыги стволов, находящиеся на высоте ниже 0,5 м и наносимые трелюемыми хлыстами (рис. 1).

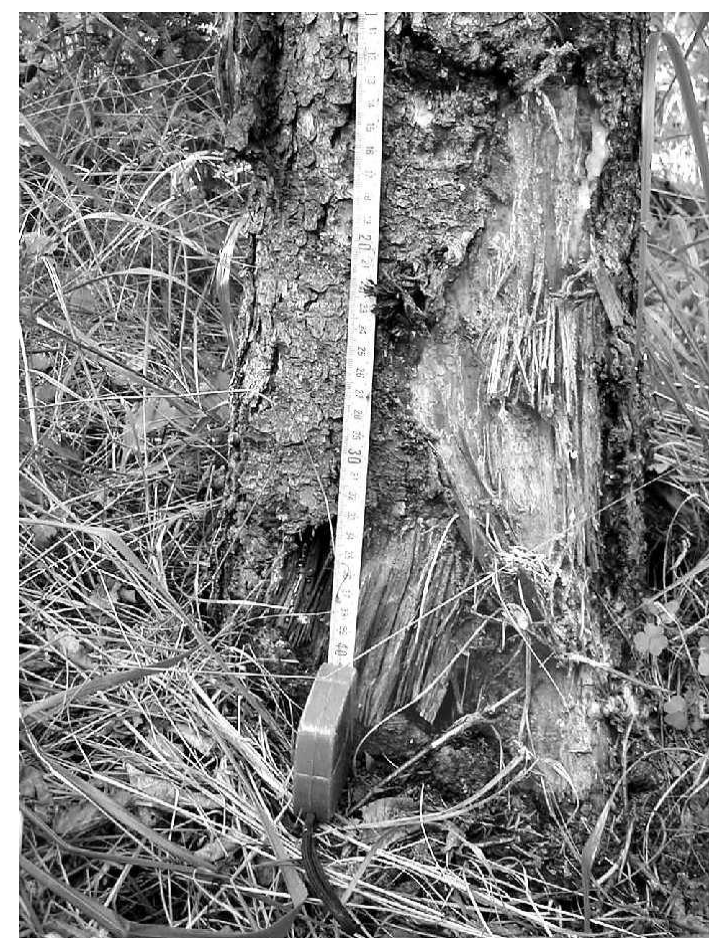

Рис. 1. Повреждения от вытаскивания хлыстов

Размеры повреждений зависят как от аккуратности выполнения работ, так и от сезона проведения рубки. На непосредственнно прилегающих к волоку деревьях доля низко расположенных ошмыгов площадью более $100 \mathrm{~cm}^{2}$ составляет около половины. На делянках сортиментной заготовки (пп 4-8) повреждения сосредоточены на высоте 1,5-2,5 м. Их ширина в зависимости от сезона заготовки колеблется от 2 до 5 см, однако общая площадь изменяется в пределах 25-135 см ${ }^{2}$ и связана $\left(\mathrm{R}^{2}=0,62\right)$ с общим количеством повреждений на делянке. Повреждения, наносимые стволам деревьев непосредственно транспортными механизмами, немногочисленны - в основном они появляются в процессе вал- 
ки деревьев и погрузки сортиментов; также незначительную часть составляют обдиры корневых лап деревьев.

Во всех случаях абсолютное большинство поврежденных деревьев оказалось сосредоточено на границах технологических коридоров.

Доля деревьев, которые было необходимо вырубить по лесоводственным соображениям, составляет 2,3-4,8\% от оставленной части древостоя; в основном они представлены сухостоем и угнетенным тонкомером.

В целом количество невырубленного сухостоя и сильно поврежденных деревьев колеблется в пределах 4,8-6,5 м /га, что не превышает 4\% наличного запаса, хотя в загущенных насаждениях, особенно с наличием нижних ярусов, оно может достигать $7 \%$.

Исследования, проведенные в Швеции [9], показали, что применение техники влечет за собой повреждение и отмирание корней в зоне технологических коридоров, особенно при проходе трактора ближе 0,7 м от дерева. В результате снижается прирост и увеличивается фаутность. Эта ситуация характерна для случаев, когда недостаточно организован уход за транспортными путями, проложенными в насаждении, и происходит образование колеи (рис. 2).

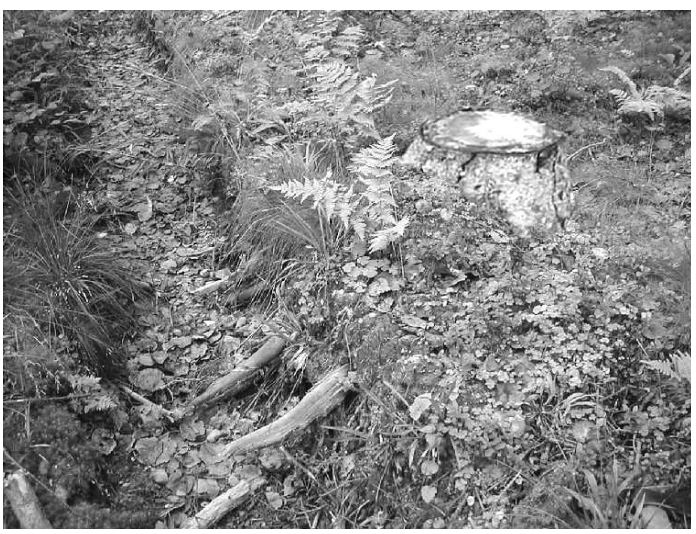

Рис. 2. Повреждение корневых лап

Ель особенно остро реагирует на повреждение корней. Через 3 года после выборочной рубки в Швеции около $40 \%$ корней ели, расположенных в зоне волоков, поражены гнилью, причем скорость ее распространения в корнях составляет 13-14 см в год. Через 9 лет гнилью поражено $90 \%$ корней, и она начинает распространяться по стволам [9].

Из приведенных данных следует необходимость постоянного укрепления поверхности почвы порубочными остатками при проведении рубок в ельниках и нецелесообразность оставления на корню деревьев ели, расположенных ближе 1 м от транспортной колеи. Даже в случае повреждения механизмами небольшой части скелетных корней совокупное воздействие этого фактора и усиленного раскачивания в результате изменения аэродинамики полога нередко вызывает разрыв корневых лап и повал дерева (рис. 3).

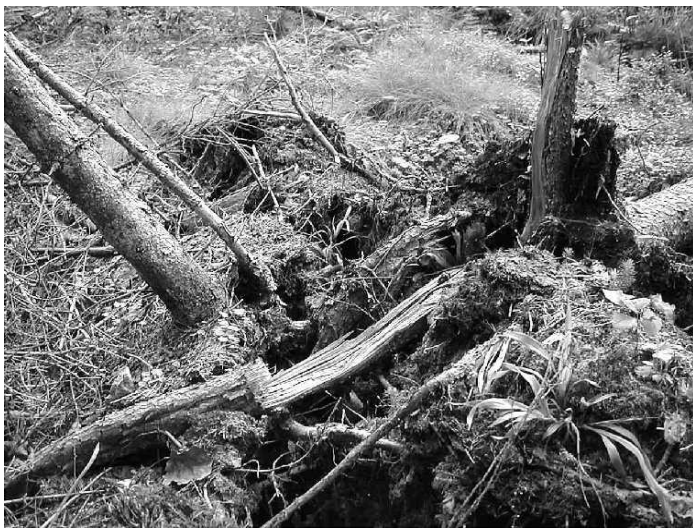

Рис. 3. Обрыв скелетных корней ели

Проведенное обследование в целом показало, что по прошествии 2 - 10 лет после разреживания древостои сохраняют хорошую устойчивость. Она обеспечивается как грамотным отбором деревьев, так и прошлой историей, в ходе которой в результате неоднократных рубок сформировались достаточно ветроустойчивые насаждения. В то же время высокая густота отдельных парцелл, сформировавшихся в достаточно больших окнах полога коренных ельников, требует повышенного внимания на фоне в среднем незагущенного насаждения. Важным фактором является также пространственная равномерность запаса древостоя, вариабельность которого не должна превышать $35-40 \%$. В связи с этим оправданным зачастую является и оставление на корню перестойных деревьев лиственных пород, вырубка которых может повлечь образование в непосредственной близости к ним сухостоя, ветровала и бурелома (рис. 4).

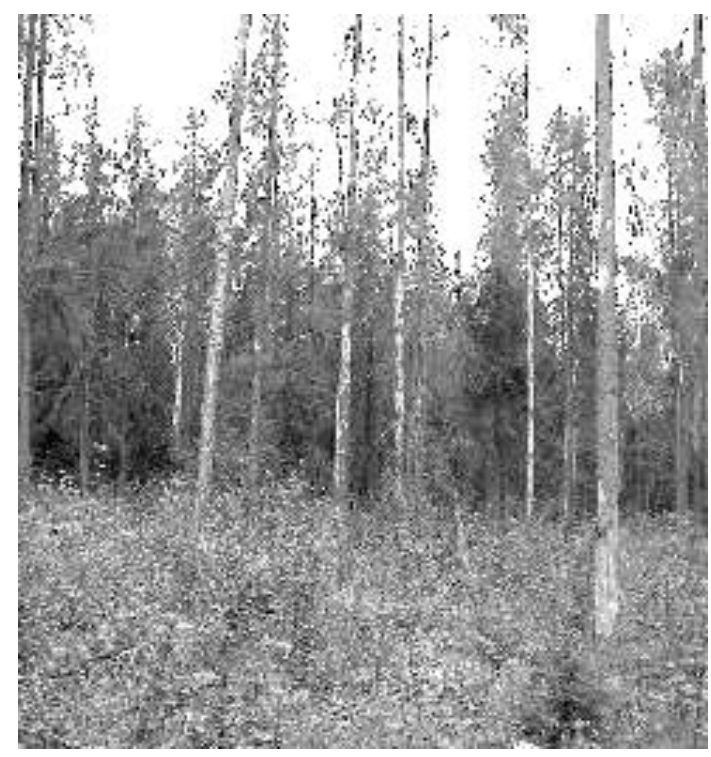

Рис. 4. Усыхание ели от чрезмерного осветления

Важнейшей характеристикой древостоев являются ряды распределения деревьев по ступеням толщины до и после проведения рубки, которые позволяют устано- 
вить товарную структуру древесины и оценить подход к назначению деревьев в рубку. В обследованных насаждениях вырубались деревья из всех ступеней толщины, однако необходимость удаления старых деревьев, которые исчерпали свои ресурсы и прирост которых становится минимальным, привела к уменьшению средних диаметров. Аналогичная картина наблюдается также в березовой и осиновой частях смешанных насаждений. В определенной мере на это влияют и обстоятельства коммерческого характера и некоторые элементы шаблонного подхода, когда определяющим критерием назначения в рубку становится диаметр дерева.

Важным аспектом лесоводственной оценки целесообразности и эффективности рубки является товарная структура вырубаемой древесины (табл. 3). Качественные показатели продукции несплошных рубок связаны с большим разнообразием влияющих на нее факторов природных и экономических. К природным факторам относятся состав и возраст насаждений, фаутность деревьев и производительность. Экономические факторы подразделяются на производственно-хозяйственные (цель рубок, интенсивность рубки, технология производственного процесса) и потребительские (структура лесопотребления, технические требования к круглым лесоматериалам, целевое назначение лесоматериалов, размеры заготовляемых сортиментов).

Природные факторы связаны с биологией древесных пород и закономерностями роста и строения древостоев. Они обусловлены различиями потребительских свойств стволовой древесины разных древесных пород и наличием в них пороков, размерами самих стволов, которые определяются условиями роста.

Таблица 3

Товарная структура вырубленной древесины (\%)

\begin{tabular}{|c|c|c|c|c|c|c|}
\hline \multirow{2}{*}{ 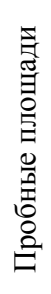 } & \multirow{2}{*}{ 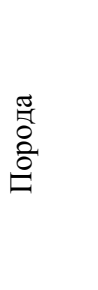 } & \multicolumn{4}{|c|}{$\begin{array}{c}\text { Деловая } \\
\text { древесина }\end{array}$} & \multirow{2}{*}{ 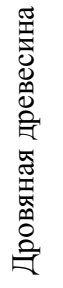 } \\
\hline & & 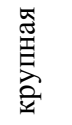 & 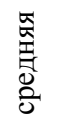 & 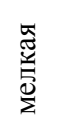 & $\begin{array}{l}0 \\
\text { b } \\
\qquad \\
\text { S }\end{array}$ & \\
\hline \multirow[t]{2}{*}{$1 п$} & Ель & 3,9 & 55,6 & 22,2 & 81,7 & 7,8 \\
\hline & Береза & 4,4 & 42,6 & 14,4 & 61,4 & 35,2 \\
\hline \multirow[t]{3}{*}{$2 \Pi$} & Ель & 25,7 & 36,4 & 17,9 & 80,0 & 8,6 \\
\hline & Сосна & 16,6 & 45,7 & 13,7 & 76,0 & 12,9 \\
\hline & Береза & 2,2 & 34,8 & 15,2 & 52,2 & 42,6 \\
\hline \multirow[t]{2}{*}{$3 \Pi$} & Ель & 30,8 & 26,1 & 13,1 & 70,0 & 22,3 \\
\hline & Береза & 3,3 & 46,7 & 21,3 & 71,3 & 21,3 \\
\hline \multirow[t]{2}{*}{ 4л } & Ель & 16,7 & 49,1 & 21,7 & 87,5 & 1,6 \\
\hline & Береза & 45,8 & 16,7 & 6,3 & 68,8 & 14,6 \\
\hline \multirow[t]{2}{*}{ 5л } & Ель & 20,9 & 44,3 & 22,1 & 87,3 & 1,9 \\
\hline & Береза & 1,0 & 62,5 & 12,5 & 76,0 & 10,6 \\
\hline \multirow[t]{3}{*}{ 6л } & Сосна & 67,8 & 23,1 & 4,5 & 95,4 & 4,6 \\
\hline & Ель & 36,7 & 30,6 & 28,6 & 95,9 & 4,1 \\
\hline & Береза & 37,5 & 42,0 & 9,7 & 89,2 & 10,8 \\
\hline
\end{tabular}

Соотношение отдельных категорий деловой древесины по крупности на разных участках варьирует в очень широких пределах. В первую очередь это связано с размерами деревьев, которые были вырублены. Березовые древостои характеризуются меньшим по сравнению с елью выходом деловой древесины, что определяется худшим качеством стволов перестойной березы. При этом также рубится значительное количество тонкомерных деревьев этой породы, которые в основном используются в качестве дров или мелких деловых сортиментов. Приведенные в табл. 3 данные не включают древесину осины, которая в связи с высокой пораженностью ложным осиновым трутовиком и отсутствием спроса целиком относится к дровяной. В то же время с учетом размеров деревьев, в соответствии с применяемыми на практике сортиментно-сортными таблицами, выход крупных и средних деловых осиновых сортиментов может достигать $65 \%$. Решение проблемы осины [2] при несплошных рубках осложняется помимо всех прочих факторов размерами и строением ее кроны, которые существенно затрудняют сохранение оставляемых на корню деревьев хозяйственно ценных пород.

По-видимому, наиболее целесообразным выходом из этой ситуации должно стать подсушивание и оставление примеси осины на корню. Это позволит избежать зачастую губительного (рис. 4) резкого изменения условий существования нижнего яруса и снизить затраты на проведение ухода за насаждением.

Аналогичным, не столь сильным, но также существенным образом сказывается на эффективности рубки пораженность грибными болезнями [8] старых деревьев ели, зачастую составляющих значительную часть вырубаемого по лесоводственным соображениям объема древесины. Тем не менее в сопоставлении с общим объемом заготовленной древесины приведенные в табл. 2 данные даже с поправкой на фаутность дают основание для уверенности в экономической эффективности проводимых рубок.

Весьма важным для выбора стратегии ведения хозяйства является вопрос естественного возобновления под пологом насаждений, пройденных рубкой, их сохранность, дальнейший рост и развитие. На всех обследованных участках, пройденных несплошной рубкой, присутствует от 250 до 1500 шт./га подроста ели. Внутри пасек он сохранился практически полностью, лишь небольшая часть его была уничтожена или сильно повреждена при валке и трелевке. Возраст, качество и размеры подроста варьируют очень сильно. Главным фактором является местоположение деревца. Те экземпляры, которые находились под пологом материнских деревьев, как правило, отличаются малыми размерами и большим возрастом. При высоте 1.5-2 м и возрасте 30-60 лет такие деревца имеют слабо развитую крону, небольшой прирост по диаметру и высоте. Они очень долго приспосабливаются к резкому изменению условий среды и могут погибнуть или в течение длительного периода сокращают прирост. Возраст и качество среднего (0.6-1.5 м) и мелкого (менее 0.5 м) подроста также значительно варьируют. Уже по прошествии од- 
ного года после рубки часть подроста начинает усыхать.

Ранее выполненные в коренных древостоях Карелии исследования влияния несплошных рубок на возобновление под пологом насаждения [7] показали неоднозначность этого хозяйственного мероприятия. Поэтому для решения лесоводственных и технологических вопросов необходимы дальнейшие исследования выживаемости, пространственного размещения и роста подроста после несплошной рубки.

Обследование, выполненное на небольшом количестве делянок, позволяет, тем не менее, сделать вывод о возможности успешного проведения предписанных действующими нормативами рубок. Накопленный в Карелии опыт их проведения на базе отечественной и импортной экономически доступной техники, несомненно, будет полезен для организации устойчивого лесопользования.

\section{СПИСОК ЛИТЕРАТУРЫ}

1. Алексеев С. В., Молчанов А. А. Выборочные рубки в лесах Севера. М.: Изд-во АН СССР, 1954.

2. Васильев И. А., Демин К. К., Волков А. Д. Проблема осины. Варианты решения: лесоводственные, экономические и организационные аспекты // Проблемы устойчивого развития лесного комплекса Республики Карелия: Научные труды КРИА. № 3. Петрозаводск, 2000. С. 18-26.
3. Воропанов П. В. Ельники Севера. М.: Гослесбумиздат, 1950.

4. Козубов Г. М. Биология плодоношения хвойных на Севере. Л.: Наука, 1974.

5. Побединский А. В. Рубки главного пользования. М.: Лесн. пром-сть, 1980.

6. Правдин Л. Ф. Сосна обыкновенная. М.: Наука, 1964.

7. Синькевич М. П. Обобщение опыта несплошных рубок в лесах Карельской АССР // Вопросы практического лесоводства в хвойных лесах СевероЗапада РСФСР: Сб.ст. Петрозаводск, 1980. С. 23-49.

8. Чибисов Г. А., Гущин В. А. Лесоводственноэкономическая оценка смены сосны елью // Лесоводственно-экономические вопросы воспроизводства лесных ресурсов Европейского Севера: Сб. ст. Архангельск, 2000. С. 137-145.

9. Чижек Яр. Биотехнические предпосылки механизации лесного хозяйства. М.: Лесная пром-сть, 1983. 